Ross, J. Cosbie, Gibbon, N. O. K. \& Damanski, M. (1967). B.f.S. 54, No. 7. StAMEY, T. (1968). F. Urol. 97, (May).

VINCENT, S. A. (I959). Ulster med. four. 28, I76.

VINCENT, S. A. (1960). Lancet, 2, 292.

Vincent, S. A. (1964). Dev. Med. and Child Neurol. 6, 23.

VINCENT, S. A. (I966a). Lancet, Sept., 63I-632.

Vincent, S. A. (I966b). Bio-Engineering, Sept., p. I.

\title{
THE ROLE OF THE EXTERNAL SPHINCTER
}

\author{
By J. Cosbie Ross \\ Director of Urological Studies, University of Liverpool
}

Introduction. It must be acknowledged that as yet no one knows the precise role of the external sphincter and there should, by right, be a question mark after the word 'sphincter'. The problem is much more complex and obscure than the simple, easily understood mechanism of the anal sphincter.

However, there is much that is already known, and perhaps recent work has shed some light on the problem.

First, the traditional view. In the 32nd Edition of Gray's Anatomy (I958), the description is as follows. 'The sphincter urethrae surrounds the membranous portion of the urethra, and lies deep to the inferior fascia of the urogenital diaphragm. Its superficial or inferior fibres arise in front from the transverse perineal ligament and from the neighbouring fascia. They pass backwards on each side of the urethra and converge on the perineal body for their insertion. Its deep fibres, some of which arise from the fascial sheath of the pudendal vessels and pass medially, form a continuous circular investment for the membranous urethra.'

Actions. 'The muscles of both sides act together as a sphincter, compressing the membranous part of the urethra. During micturition they, like the bulbocavernosus, are relaxed, and only come into action at the end of the process to eject the last few drops of urine.'

The authors go on to describe the transverse perineal ligament as the thickened apical part of the inferior fascia of the urogenital diaphragm attached laterally to the inferior pubic rami. There is no doubt that this classic description has been modified by the work of recent investigators. Firstly, Bors (1954) has shown many years ago that the original tidy concept of striated muscle fibres being confined between the two layers of the urogenital diaphragm was incorrect as he found striated muscle extending up the prostatic urethra to the bladder neck, being especially marked at the anterior commissure. Confirmation of this was afforded by the fact that during the years of 1952 to 1956 (when the writer carried out the operation of pudendal neurectomy for obstruction at the external sphincter, and before it was realised that division of the muscle was a better procedure) it was found that following the operation the whole posterior urethra frequently opened out and relaxed.

In a histological study Beneventi and Marshall (1956) found that the fibres of the external sphincter blended with the prostatic capsule, extending dorsally 
almost to the vesical outlet. Like others, they did not find the traditional circumferential pattern and pointed out that the external sphincter level of continent patients moved upwards for a distance of an inch, on voluntary stoppage of micturition.

Lawson (1967), as a result of a number of dissections of the neonatal pelvis, found that the lower part of the muscle arises from the pubic arch, passing medially round the urethra to be inserted into the contralateral aspect of the perineal body and encircles the urethra to find attachment on the opposite side of the perineal body. He points out that whereas in the more distal part the fibres are horizontal,

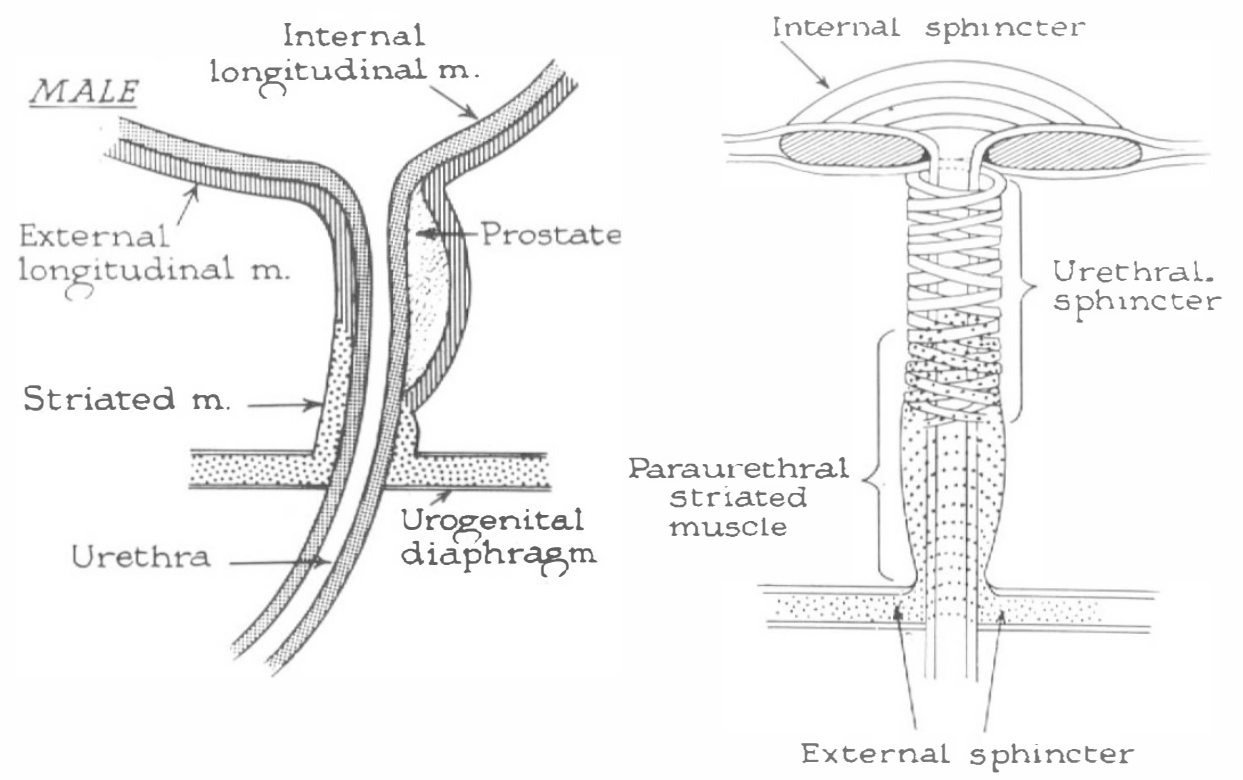

FIGS. I and 2

The bladder neck and external sphincter (after Hutch).

the more proximal fibres are oblique or spiral on the vertical aspect of the urethra, blending above with the smooth muscle of the bladder base. Lawson concludes by pointing out that striated muscle fibres do not completely encircle the urethra at any level, the gap being completed posteriorly by the perineal body and the bladder neck. Now to pass on to the interesting concept recently put forward by Hutch and Rambo (1967). Hutch describes three sphincters associated with the posterior urethra (figs. I and 2).

I. The first is the internal sphincter, which is derived from the anterior portion of the base-plate and consists of smooth muscle. This structure encircles the internal urinary meatus, remaining closed so long as the base-plate is flat.

2. The second (which he calls the urethral sphincter) is continuous with the outer longitudinal layer of the bladder and is also formed of smooth muscle. The sphincter is limited to the upper half of the posterior urethra, and Hutch believes that it is this muscle which squeezes back into the bladder the residual few drops of urine present in the prostatic urethra at the close of micturition. He quotes 
Endhorning, who found that the intraluminal pressure was higher in the upper half of the posterior urethra than in the lower portion, which is surrounded by the striated external sphincteric fibres.

3. The third is the external sphincter muscle. Now it is postulated that in addition to those fibres lying sandwiched between the urogenital diaphragm there are also striated fibres round the lower half of the posterior urethra. These paraurethral fibres are also capable of constricting the lumen. Hutch and Rambo believe that the para-urethral part of the external sphincter is responsible for initiating voiding by pulling downwards the base plate, rendering it a cone-shaped and not a flat structure. Consequently, the ascent of the prostatic urethra after the conclusion of voiding would appear to be a passive relaxation of this muscle. Immediately, then, it would appear that the role of the external sphincter is more complex than the simple traditional view of a circular muscle compressing the lumen of the membranous urethra.

Investigation. It is generally agreed that it is difficult to investigate the external sphincter and its effect on continence on account of the number of other factors present, such as the dense elastic tunica propria of the urethra, the internal sphincter, the falling together of the urethral walls, etc., but there is one condition particularly favourable to such an investigation. This is the post-prostatectomy state in which all these other factors (helping to ensure continence under normal conditions) have been removed by operation, thus leaving continence dependent on the external sphincter muscle alone. Some years ago Tinckler and the writer devised a simple method of sphincterometry in which water was run into the anterior urethra through a catheter, leakage being prevented by applying an external penile clamp. At lower pressures the water ran in slowly, drop by drop, but at a certain point (where the resistance of the external sphincter was overcome) the flow became continuous. It was found that a pressure of $80 \mathrm{~cm}$. of water was necessary for full continence, anything less than this being accompanied by urethral leakage on coughing, straining or even getting out of bed (Cosbie Ross and Tinckler, 1959). Bors (1967), using a more sophisticated method of sphincterometry, demonstrated that lower pressures, i.e. 20 to $40 \mathrm{~mm}$. $\mathrm{Hg}$, were found in the lower motor neurone lesions, whereas the pressures were 80 to $100 \mathrm{~mm}$. $\mathrm{Hg}$, or higher, in upper motor neurone injuries. He compares the finding of sphincterotomy with the presence of the bulbocavernosus reflex and sphincter tone.

On the other hand, the view that there are several factors maintaining continence under normal circumstances is supported by the fact that pudendal neurectomy (Ross and Damanski, I953), or division of the external sphincter (Ross, Gibbon and Damanski I963), leads only to a minor degree of stress incontinence if all the other factors such as the base plate, the elastic tunica propria and the prostate are all present. Again, if all these other factors are eliminated (as in suprapubic prostatectomy), the external sphincter is still capable of maintaining continence. Possibly the external sphincter acts like the hand-brake of a car; when the hand-brake is applied the car comes to a stop and does not necessarily start to move again when the hand-brake is released. Not all authorities, however, agree with this view. Caine and Edwards (1958), as a result of studies using the image intensifier, have put forward the concept of active and passive continence. Active continence, in their view, occurs during voluntary interruption of voiding and is the responsibility of the external sphincter muscle. Passive continence is 
maintained between the acts of voiding and is due to the tone of the smooth muscle plus the fibro-elastic muscular sheath lying beneath the uro-epithelium of the posterior urethra. They believe that (after prostatectomy) the column of opaque fluid does not stop at the external sphincter level, but slightly above this point. It is difficult to correlate this view with the fact that the fibro-elastic muscular subepithelial sheath disappears after prostatectomy and yet these patients are continent.

Adran and his colleagues (I967) in a series of experiments suggest that the important sphincteric mechanism is situated at the bladder neck, and that the animal remains continent after the urethra has been severed at the vesico-urethral junction. This view, however, is not generally acceptable, not only because of the other factors obviously involved but also because it would seem unlikely that the complex sphincteric mechanism of the posterior urethra is without purpose.

The writer prefers the concept expressed both by Woodborne (I960) and Lapides (1960) that the bladder neck and posterior urethra should be regarded as a 'sphincter region' rather than consisting of individual internal and external sphincter. This concept is based on the free blending of smooth and striated muscle, combined with the fact that the posterior urethra is a tube, frequently altering its length, its shape and its tension.

Barkin (1967), following dissections in the embryo, argued that continence is influenced by:

I. The base plate.

2. The dense elastic tunica propria of the urethra.

3. The circular smooth muscle of the posterior urethra.

4. The intra-abdominal situation of the upper two-thirds of the posterior urethra, making a built-in defence against incontinence.

5. The complex parts of the striated external sphincter.

Some interesting ciné-radiographic studies have been carried out by Ascoli and Franch (1966) in which they found that in 94 per cent. of paraplegic patients the bladder neck was opened fully and even more widely than normal when voiding. In the great majority of their patients the prostatic urethra was dilated but the external sphincter failed to relax during micturition. Their conclusions were that, in the neurogenic bladder, the commonest obstruction was the external sphincter and not situated at the bladder neck. Similarly, Scott (1967) states that few of his patients appear to have obstruction at the bladder neck. On the other hand, he says the external sphincter does not relax and the pelvic floor fails to descend. Scott adds that the voltage potential of the sphincter increases rather than decreases. Similarly, Semens (1967) says 'After the urethra has been completely divided precisely at the junction of the urogenital diaphragm and the apex of the prostate, the bladder emptied itself, proving that this was the one remaining segment of the urethra which was obstructed after transurethral resection'.

Campbell (1967) makes the bold suggestion of crushing both pudendal nerves in all patients admitted with spinal cord injury, with the object of obviating the use of a catheter. He says the pudendal nerves will regenerate, but it is obvious that this suggestion is out of the question, certainly in the case of women. These observations confirm the view which the writer has maintained for over I 2 years (Cosbie Ross, 1956). It is only in the last few years that the importance of the external sphincter has been widely appreciated. 
This obstructive factor at the external sphincter level is, then, partly associated with the fact that in the automatic bladder contraction of the detrusor is not accompanied by descent of the bladder base, and the urinary stream encounters resistance from the unrelaxed external sphincter.

It was thought at first that the actual obstructive factor was a mechanical one, associated with inflammatory changes and rigidity at that level, but it was soon realised that the hold-up was a spastic sphincter, but a better term would be that suggested recently, of detrusorsphincter dyssynergia (Cosbie Ross, Gibbon and Damanski, I967).

Clinical Aspects. Now to turn to the clinical aspects of the problem Probable reasons why division of the external sphincter is effective in the treatment of selected cases of neurogenic bladder include the following:

I. Firstly, the external sphincter may be spastic in the same manner as the skeletal muscles. Sometimes relaxation may be achieved by the administration of valium.

2. Secondly, the muscle fails to relax in reciprocal reflex action when the detrusor contracts.

3. Thirdly, a condition similar to the structural secondary organic changes seen in the neglected spastic bladder may develop in the external sphincter.

4. Fourthly, the benefits from the operation may be in part due to the myotomy eliminating sensory impulses in a manner similar to that arising in a spastic limb.

With regard to the technique, the operation is carried out through an operating urethroscope with a Colling's diathermy knife, the actual division being situated postero-laterally. The upper limit of the cut is at the level of the lowest point of the verumontanum, an actual ridge or hump being frequently appreciated by the extremity of the urethroscope. To prevent bleeding, the area is diathermied by the coagulating current before the division is made. Using this technique there is little or no trouble with post-operative bleeding.

Effect on Bladder Emptying. Of 65 patients, two died during the postoperative period and there were five failures. In the remaining 58, the residual urine and infection were either eliminated or considerably reduced. Of the five failures, one was a tetraplegic in poor condition, and it seems probable that the muscle was insufficiently divided on the first occasion and his general condition was too poor to repeat the procedure. The other four failures were in neurogenic bladders of medical origin with the many difficulties attending these, especially in disseminated sclerosis.

Effect on the Upper Urinary Tract. Out of 65 patients (subjected to division of the external sphincter), 42 had a normal upper urinary tract, while the remaining 23 had some degree of hydronephrosis. After the operation the hydronephrotic changes disappeared in six and were considerably improved in four. As we have shown previously, improvement of hydronephrosis (and indeed of ureteric reflux) is less likely to follow removal of obstructive factors if there is already present gross diverticulosis and trabeculation of the bladder, especially in the presence of cavitation of the prostate (Cosbie Ross, Gibbon and Damanski, I960). 


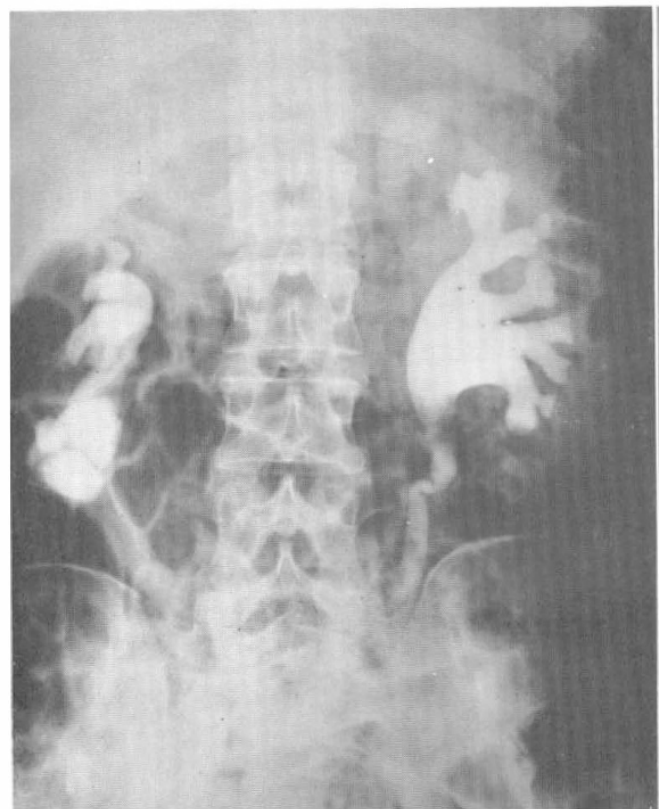

FIG. 3

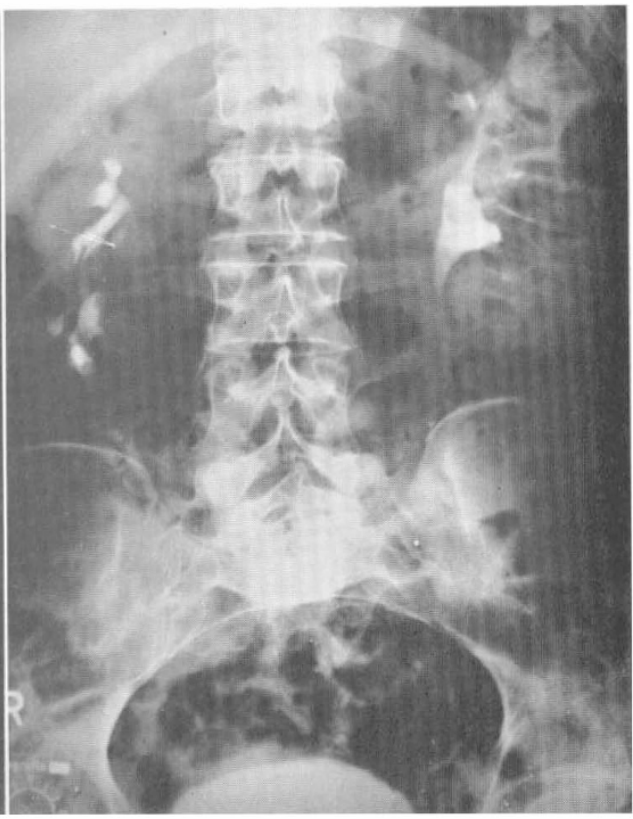

FIG. 4

Fig. 3.-I.V.P. before division of the external sphincter.

Fig. 4.-I.V.P. after division of the external sphincter.

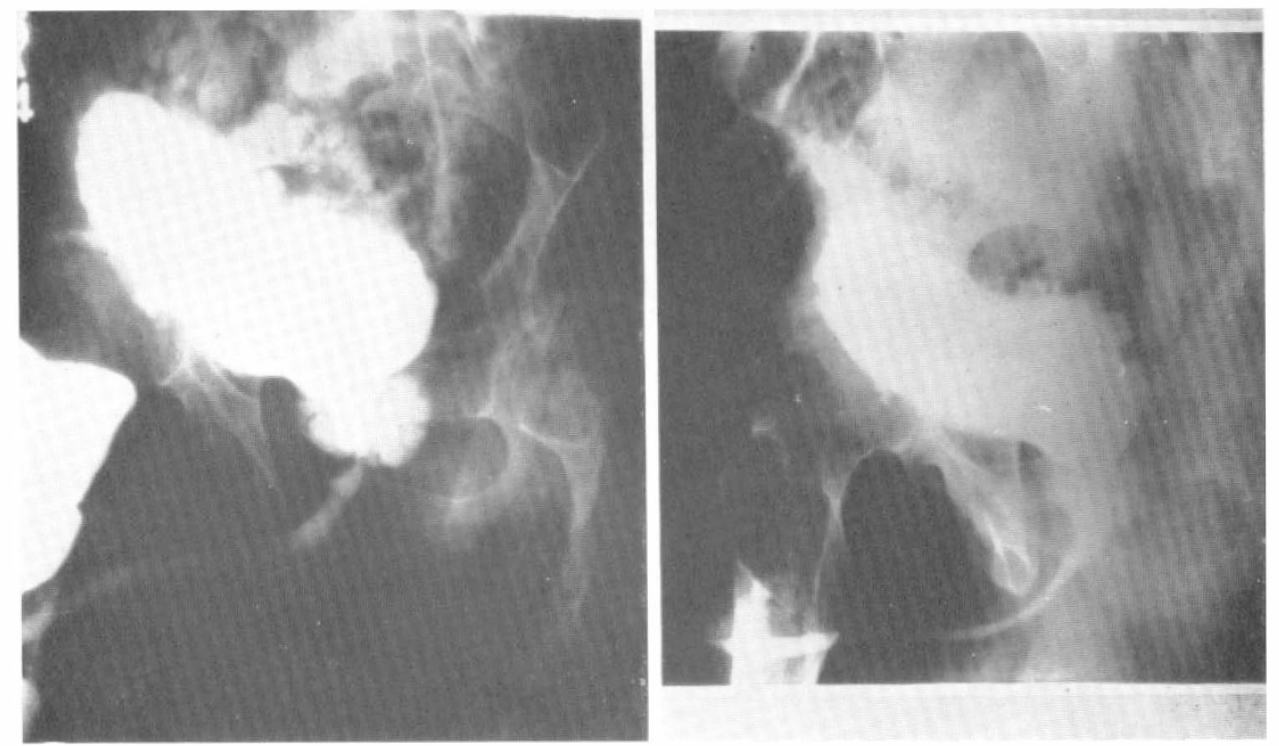

Fig. 5

Cysto-urethrogram before and after division of the external sphincter. 
Sometimes the operation has a dramatic effect as is shown in Figures 3 to 5 .

Conclusions. At this stage it is perhaps premature to attempt to define the function of the external urethral sphincter. It is, however, permisseble to state certain facts and to make some certain suggestions:

I. The structure of the external sphincter is more complex and extensive than previously thought, part of it extending upwards around the prostatic urethra, above the urogenital diaphragm.

2. Division of the muscle leads only to a minor degree of stress incontinence because of the other factors helping to maintain continence.

3. The muscle is capable of maintaining continence unassisted, as after prostatectomy.

4. In the neurogenic bladder the muscle does not relax reciprocally with detrusor contraction.

5. In the neurogenic bladder the obstructive factor is frequently present at the external sphincter level.

6. The operation of division of the external sphincter provides a safe and effective method of dealing with such obstruction.

Finally, the writer wishes to pay a warm tribute to John Emmett, who has done so much for the neurogenic bladder and wrote a thoughtful and interesting paper on the function of the external sphincter over 20 years ago (Emmett, I948).

\section{REFERENCES}

Adran, J. M., Cope, V., Essenhigh, D. M. \& Tuckey, M. (1967). Br. F. Urol. 29, 334. Ascoli, R. \& Franch, L. (I966). Urologia, Treviso, 33, 284.

BARKIN, M. (1967). Personal Communication.

Beneventi, F. A. \& Marshall, V. F. (1956). F. Urol. 75, 273.

Bors, E., ComarR, A. E. \& ReIngold, I. M. (I954). F. Urol. 72, I9I.

Bors, E. (1967). In Neurogenic Bladder, ed. Boyarski, S., p. 7I. Baltimore : Williams and Wilkins.

Caine, M. \& Edwards, D. (1958). Br. F. Urol. 30, 34.

CAMPBell, J. B. (I967). In Neurogenic Bladder, ed. Boyarsky, S., p. I26. Baltimore: Williams and Wilkins.

EMmETt, J. et al. (1948). f. Urol. 59, 439.

GRAY's Anatomy, 32nd Ed., p. 609. London : Longmans.

Hutch, J. A. (I967). f. Urol. 97, 705.

Hutch, J. A. \& Rambo, O. (1967). F. Urol. 97, 696.

LAPIDES, J. et al. (1960). F. Urol. 84, 86.

Ross, J. C. (1956). Br. F. Urol. 28, I4.

Ross, J. C. \& DAMANSKI, M. (I953). Br. f. Urol. $25,45$.

Ross, J. C., Gibbon, N. O. K. \& Damanski, M. (1960). Br. F. Surg. 47, 636.

Ross, J. C., Gibbon, N. O. K. \& Damanski, M. (I963). F. Urol. 89, 692.

Ross, J. C., Gibbon, N. O. K. \& Damanski, M. (I967). Br. F. Surg. 54, 627.

Ross, J. C. \& TinckLer, L. (I959). Br. med. F. 2, 663.

ScotT, F. B. (1967). In Neurogenic Bladder, ed. Boyarsky, S., p. 132. Baltimore: Williams and Wilkins.

Semans, H. (1967). In Neurogenic Bladder, ed. Boyarsky, S., p. I33. Baltimore : Williams and Wilkins.

WoOdBorne, R. T. (1960). F. Urol. 84, 79. 